\title{
Study Of Nutrient Foramina In Adult Human Femur Bones
}

\author{
Gupta $\mathrm{AK}^{1}$, Ambekar $\mathrm{MN}^{2}$
}

\begin{abstract}
Background: The role of nutrient foramen (NF) in nutrition and growth of the bones is evident from term Nutrient itself. The nutrient foramen is opening of nutrient canal on the surface of shaft of the bone which conducts the nutrient artery and the peripheral nerves to bones. Long bones receive most of the interosseous blood supply (70\% to $80 \%$ ) from the nutrient arteries and remaning (20\% to $30 \%$ ) through the periosteal vessels. Nutrient arteries play an important role in nutrition and growth of the bones particularly during early phases of ossification and growth. The present study is of great importance to orthopedic surgeons in planning repair of fracture, amputation and bone grafting procedures. Aim and objective of study: A study regarding nutrient foramina in femur was not conducted in the past in Nepal. Its importance in orthopedic procedures has inspired us to undertake this study. Materials and methods: This study was conducted on 100 adult dry femur bones ( 50 right and 50 left). All the important parameters were studied using osteometric board, vernier calipers, and needles of different gauges. Results: Mean distance of nutrient foramen from upper end was $18.09 \mathrm{cms}$. The most common location of NF was on lateral surface $58.8 \%$. In $71 \%$ femur only one NF was seen, while $25 \%$ had two NF, $1 \%$ femur had three NF and $3 \%$ femur had no NFs. In $64.5 \%$ femur big size or dominant NFs were seen in present study. Conclusions: The findings of this study on nutrient foramen adds to the information from studies in the past by other authers. The fact that maximum number of the nutrient foramina are present in the middle third of the shaft of the femur is of clinical importance for proper diagnosis, planning of surgery and predict the prognosis.
\end{abstract}

Keywords: Femur, nutrient foramina, nutrient artery

\section{INTRODUCTION}

The femur is the long bone of the thigh. Femur is the bone which is susceptible to the functional and hormonal disturbances, aging process and physical trauma which account for its usual fractures and dislocations ${ }^{1}$. The arteries supplying this long bone enter into it via numerous foramina located over its different segments, being named as vascular foramina. Among these vascular foramina, nutrient foramen is an important one which gives way to the nutrient artery ${ }^{2}$.

The nutrient foramen (NF) is defined as the largest of the foramen present on the shaft of long bone allowing nutrient artery to enter the bone, the role of which is important in providing nutrition and growth of the long bones. One or two main diaphyseal nutrient arteries enter the shaft obliquely through nutrient foramen leading into nutrient canals. Their sites of entry and angulation are almost constant and characteristically directed away from the growing epiphysis ${ }^{3}$.

Precise knowledge of nutrient foramen and its variations is necessary for doctors to predict prognosis of grafts, tumors, fractures of bones ${ }^{4}$ and also useful for anthropologist during

1. Dr. Anil Kumar Gupta

2. Prof. M. N. Ambekar

Address for correspondence

Dr. Anil Kumar Gupta

Department of Anatomy

Nepalgunj Medical College

Chisapani, Banke, Nepal.

Email:dr.anilkugupta@gmail.com interpretation of height from a fragment of bone in medicolegal cases $^{5}$. It is also helpful in early identification of vascular interruption leading to osteonecrosis ${ }^{2}$.

Considering all the above facts, aim of the present study was to note the morphology and variations of the nutrient foramen in human adult dry femur bones, available at Department of Anatomy, Nepalgunj Medical College, Chisapani, District Banke, Nepal. Study is helpful to highlight its clinical importance and also to add our data for further studies.

\section{MATERIALS AND METHODS}

A study of nutrient foramen morphology was conducted on total of 100 (50 right and 50 left ) dry adult human femur bones of unknown age and sex, from the collection in the Department of Anatomy, Nepalgunj Medical College, Chisapani, District Banke, Nepal. Deformed and damaged bones with callous formation were excluded from the study. The instruments used for the study were as follows and shown in Figure 1.

1) Osteometric board: Used for measuring total length of bone.

2) Vernier caliper: To measure distance of nutrient foramen from upper end.

3) 18, 20, 22, 24 gauge hypodermic needles: Used for measuring caliber of nutrient foramina.

4) Magnifying lens: To find the nutrient foramen.

5) Numbering sticker (Radium): The dry adult human femur bones were numbered using the numbering sticker from 1 to 100 numbers in serial order. 


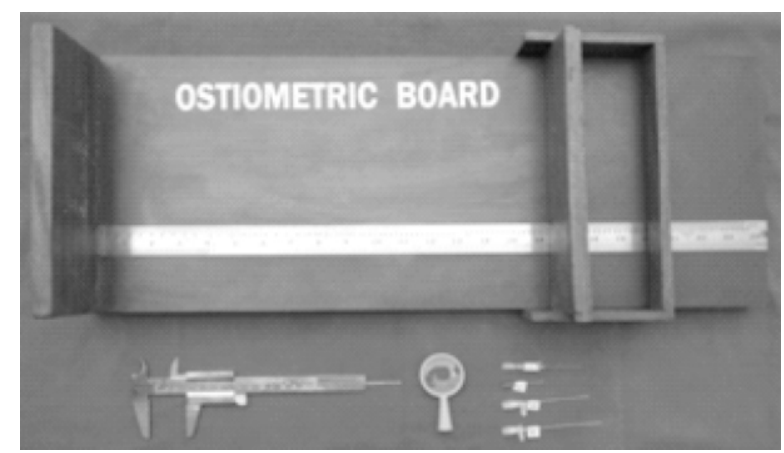

Figure 1: Instruments used in the study

Each femur was numbered serially with numbering sticker to help in identification. Their side (left or right) was determined. The diaphyseal nutrient foramina were observed in all the bones with a hand-lens. Various parameters were recorded for each of the femur. Total length and distance of nutrient foramen from upper end were measured in centimeters. Locations of nutrient foramen and number of foramen were also noted in relations to surfaces. The sizes of nutrient foramen were measured with the help of hypodermic needles of $18 \mathrm{G}$ to $24 \mathrm{G}$.

Following parameters were studied:

\section{The total length}

The total length of each femur was measured with the help of osteometric board (Figure 2) and total length was recorded in centimeters. Determination of the total length of the individual bones was done by taking the measurement between the superior aspect of the head of the femur and the most distal aspect of the medial condyle. After measuring all the bones the 'range of total length' and the 'mean of total length' for femur was obtained.

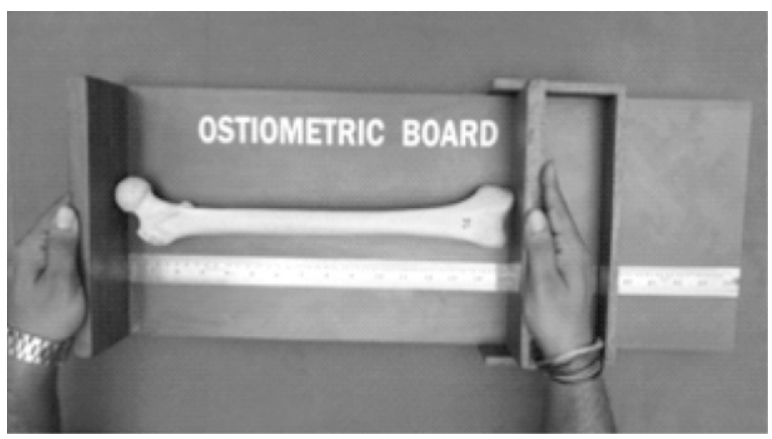

Figure 2: Measuring the length of femur

\section{Total number of nutrient foramina}

The nutrient foramina were observed in all the bones carefully with the help of hand-lens and the total number of foramina present on any surface was recorded. In bones where there was doubt as to the nature of a foramen, a fine wire was passed through it to confirm that it did enter the medullary cavity (Figure 3).

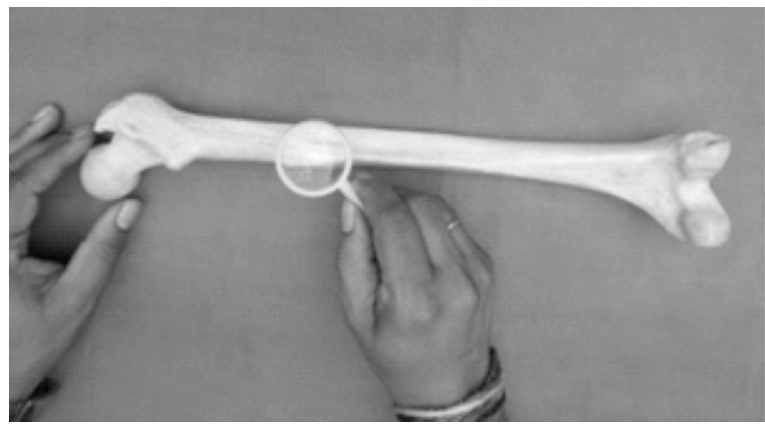

Figure 3: Observing the nutrient foramen with the help of lens

\section{The distance of the nutrient foramen from the upper end} of the bone:

The distance of the nutrient foramen from the upper end of the bone was measured with the help of sliding vernier caliper and recorded. The range and the mean distance of nutrient foramen from upper end was calculated and recorded (Figure 4).

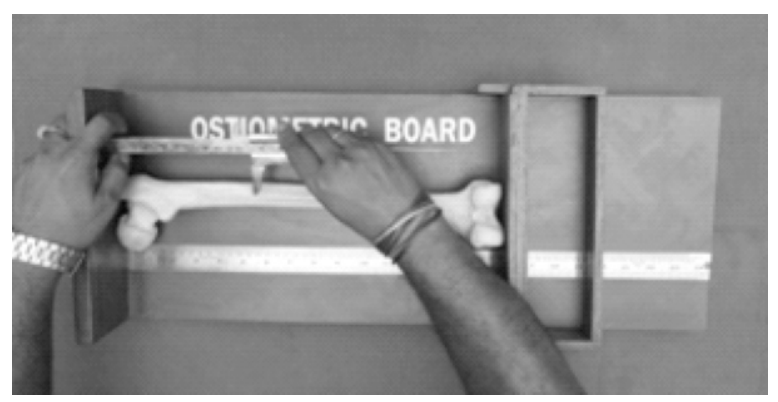

Figure 4: Measuring the distance of nutrient foramen from upper end

\section{The location of nutrient foramen}

All the surfaces of the bones were scrutinized in a regular order. Foramina within $1 \mathrm{~mm}$ from any border were taken to be lying on that surface. The location of the nutrient foramen was also recorded in relation to the segment of the bone it occupied. For this the femur was divided into three segments (proximal, middle and distal) ${ }^{6}$.

\section{Caliber of the foramen}

Hypodermic needles of gauge 18 to gauge 24 were used to measure the caliber of the foramen. If the needle of $18 \mathrm{G}$ size 


\section{The location of nutrient foramen}

All the surfaces of the bones were scrutinized in a regular order. Foramina within $1 \mathrm{~mm}$ from any border were taken to be lying on that surface. The location of the nutrient foramen was also recorded in relation to the segment of the bone it occupied. For this the femur was divided into three segments (proximal, middle and distal). ${ }^{6}$

\section{Caliber of the foramen}

Hypodermic needles of gauge 18 to gauge 24 were used to measure the caliber of the foramen. If the needle of $18 \mathrm{G}$ size passed through the nutrient foramen satisfactorily, it was classified as 'large' sized. If the needle of $24 \mathrm{G}$ size passed through the foramen, it was classified as 'small' size. If the needle of the 20G to $22 \mathrm{G}$ size passes through the nutrient foramen it was classified as 'medium' sized. Both large and medium-sized foramen was also categorized as being 'dominant'. If the needle of $24 \mathrm{G}$ size could pass or could not pass through the foramen it was classified as 'small' sized or 'accessory' nutrient foramen.

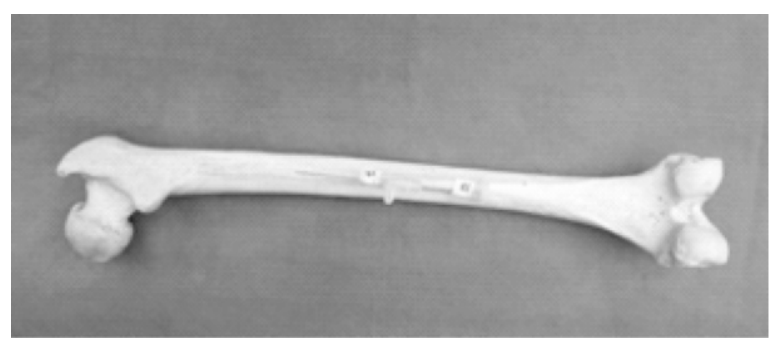

Figure 5: Measuring the caliber of nutrient foramen

\section{RESULTS}

The total number of femur bones examined was 100 , out of which 50 were of right and 50 were of left side. The details of parameters summarized in Table I-V. Total length of the femur ranged from $36.1-46.4 \mathrm{cms}$ and the mean value was 41.22 . Total number of nutrient foramina studied was 124 and the mean distance of nutrient foramen from upper end was found to be $18.00 \mathrm{cms}$. Out of 124 nutrient foramina studied, 25 were of big size ( $18 \mathrm{G}), 55$ of medium size (20G $-22 \mathrm{G}$ ) and 44 were of small size (24G). There were 71 bones with 1 nutrient foramen, 25 bones with 2 nutrient foramina, 1 femur with 3 nutrient foramina, 3 femora did not show any nutrient foramen. The most common location for the nutrient foramen was on the lateral surface in 73 bones. On dividing the femur into 3 segments (proximal, middle and distal), the most common location of nutrient foramen was found on the middle third in 97 femora and next common were on the proximal third in 26 femora.

\section{DISCUSSION}

The principal nutrient vessels of a long bone are first indicated in late embryonic life (eighth week) by a localized vascular irruption into the midpoint of the cartilaginous primordium and at right angles to it. During embryonic development the initial nutrient artery lies at the central point and at right angles to the bone. The explanation of the displaced location of the foramen and the obliquity of the canal in an adult bone is usually said to be due to continued growth at growing end of the bone. ${ }^{7}$

Gray's anatomy text book describes, the foramina for the nutrient arteries are situated close to the linea aspera. ${ }^{6}$ They

\begin{tabular}{|c|c|c|c|}
\hline Side & Total no. of bones examined & Range of total length $\mathbf{( c m )}$ & $\begin{array}{c}\text { Mean of total length } \\
\text { (cm) }\end{array}$ \\
\hline Right & 50 & $36.1-44.5$ & 40.75 \\
\hline Left & 50 & $37.3-46.4$ & 41.68 \\
\hline Both & 100 & $36.1-46.4$ & 41.22 \\
\hline
\end{tabular}

Table I: General observation about the total length of femur.

\begin{tabular}{|c|c|c|c|c|c|c|}
\hline Side & $\begin{array}{c}\text { Total no. of } \\
\text { bones } \\
\text { examined }\end{array}$ & $\begin{array}{c}\text { Total no. of } \\
\text { foramina }\end{array}$ & $\begin{array}{c}\text { No. of bones: } \\
\text { NF not seen }\end{array}$ & $\begin{array}{c}\text { No. of bones } \\
\text { with 1 NF }\end{array}$ & $\begin{array}{c}\text { No. of bones } \\
\text { with 2 NF }\end{array}$ & $\begin{array}{c}\text { No. of bones } \\
\text { with 3 or } \\
\text { more NF }\end{array}$ \\
\hline Right & 50 & 67 & 02 & 30 & 17 & 01 \\
\hline Left & 50 & 57 & 01 & 41 & 08 & 00 \\
\hline Both & 100 & 124 & 03 & 71 & 25 & 01 \\
\hline
\end{tabular}

Table II: General observation regarding the number of nutrient foramen. 


\begin{tabular}{|c|c|c|c|c|}
\hline Side & $\begin{array}{c}\text { Total no. of bones } \\
\text { examined }\end{array}$ & $\begin{array}{c}\text { Total no. of } \\
\text { foramina }\end{array}$ & $\begin{array}{c}\text { Range of distance of } \\
\text { NF from upper end }\end{array}$ & $\begin{array}{c}\text { Mean of distance of } \\
\text { NF from upper end }\end{array}$ \\
\hline Right & 50 & 67 & $11.5-31.5$ & 18.09 \\
\hline Left & 50 & 57 & $12.8-25.3$ & 17.91 \\
\hline Both & 100 & 124 & $11.5-31.5$ & 18.00 \\
\hline
\end{tabular}

Table III: General observation about the distance of nutrient foramen from upper end.

\begin{tabular}{|c|c|c|c|c|c|c|}
\hline Side & $\begin{array}{c}\text { Total no. of } \\
\text { bones } \\
\text { examined }\end{array}$ & $\begin{array}{c}\text { Medial } \\
\text { surface }\end{array}$ & $\begin{array}{c}\text { Lateral } \\
\text { surface }\end{array}$ & Medial lip & Lateral lip & Linea aspera \\
\hline Right & 50 & 24 & 31 & 12 & 00 & 00 \\
\hline Left & 50 & 09 & 42 & 04 & 02 & 00 \\
\hline Both & 100 & 33 & 73 & 16 & 02 & 00 \\
\hline
\end{tabular}

Table IV. (a): General observation about the location of nutrient foramen in relation to surface.

\begin{tabular}{|c|c|c|c|c|c|}
\hline Side & $\begin{array}{c}\text { Total no. of } \\
\text { bones examined }\end{array}$ & $\begin{array}{c}\text { Total no. of } \\
\text { foramina }\end{array}$ & $\begin{array}{c}\text { Proximal 1/3 } \\
\text { segment }\end{array}$ & $\begin{array}{c}\text { Middle 1/3 } \\
\text { segment }\end{array}$ & $\begin{array}{c}\text { Distal 1/3 } \\
\text { segment }\end{array}$ \\
\hline Right & 50 & 67 & 20 & 46 & 01 \\
\hline Left & 50 & 57 & 06 & 51 & 00 \\
\hline Both & 100 & 124 & 26 & 97 & 01 \\
\hline
\end{tabular}

Table IV (b): General observation about the location of nutrient foramen in relation to segment.

\begin{tabular}{|c|c|c|c|c|c|c|}
\hline \multirow[t]{2}{*}{ Side } & \multirow{2}{*}{$\begin{array}{c}\text { Total no. of } \\
\text { bones } \\
\text { examined }\end{array}$} & \multirow{2}{*}{$\begin{array}{l}\text { Total no. of } \\
\text { foramina }\end{array}$} & \multirow{2}{*}{$\begin{array}{l}\text { large size (18 } \\
\text { gauge) }\end{array}$} & \multicolumn{2}{|c|}{ Medium size } & \multirow{2}{*}{$\begin{array}{l}\text { small size } \\
\text { (24 gauge) }\end{array}$} \\
\hline & & & & 20 gauge & 22 gauge & \\
\hline Right & 50 & 67 & 16 & 13 & 14 & 24 \\
\hline Left & 50 & 57 & 09 & 08 & 20 & 20 \\
\hline Both & 100 & 124 & 25 & 21 & 34 & 44 \\
\hline
\end{tabular}

Table V: General observation about the size of nutrient foramen in gauge size.

vary in number and position. One is usually at the upper end of the linea aspera, and a second, which is not always present, near its lower end. The foramina are directed upwards through the compact bone. The nutrient artery of the femur usually comes from the second perforating artery, which is one of the three perforating branches from the profunda femoris artery. When two nutrient foramina exist, they usually come from the first and third perforating branches of above artery. Textbook of anatomy by Henry Hollinshead describes that the body of the femur receives small blood vessels from the periosteal vessels, but its chief supply is from one or two nutrient arteries, which are usually derived from the upper perforating branches of the profunda femoris artery, and enter the posterior surface of the femur close to the linea aspera. ${ }^{8}$ Morris human anatomy describes that near the center of the linea aspera is the nutrient foramen conducting the nutrient artery into the nutrient canal directed towards the proximal end of the bone. ${ }^{9}$ The blood supply of the shaft is derived from either the second or third perforating artery or from two nutrient vessels arising usually from the first and third perforating arteries, branches of profunda femoris artery.

The present study was undertaken because no such data regarding nutrient foramina was available from Nepal. So, in the present study 100 femora were used. Out of 100 femora, 50 were of right side and 50 were of left side. Kizilkanat et a $\mathrm{a}^{10}$ have used 100 femora, Mysorekar ${ }^{11}$ has used 180 femora, Laing ${ }^{12}$ has used 10 femora, Bridgeman ${ }^{13}$ et al used 109 femora, 
Motabagani ${ }^{14}$ has studied 130 femora and Gupta RK et al ${ }^{7}$ used 312 femur bones.

\section{The total length (TL)}

The mean total length obtained in the present study is 41.22 cms, which is almost similar to the results obtained by the previous authors, and are shown in Table VI.

\section{Number of nutrient foramina}

In the present study the femur bone had variable number of nutrient foramina, ranging from 1 to 3 , on a single bone. On comparing the result of the present study with other authors who have done similar study earlier. Our result was similar to that of the Kizilkanat et al, ${ }^{10}$ except that we have found $3 \%$ of bones without nutrient foramen, as shown in Table VII.

\begin{tabular}{|l|c|}
\hline Author & Mean total length of the bone \\
\hline Kizilkanat et al $^{10}$ & $42.58 \mathrm{cms}$ \\
\hline Nagel $^{15}$ & $40.1 \mathrm{cms}$ \\
\hline Kirschner et al & $40.8 \mathrm{cms}$ \\
\hline Roopam et al & $43.23 \mathrm{cms}$ \\
\hline Present Study & $41.22 \mathrm{cms}$ \\
\hline
\end{tabular}

Table VI: Comparison of the mean total length of the bone.

\begin{tabular}{|c|c|c|c|c|c|}
\hline Author & $\begin{array}{l}\text { No. of } \\
\text { bones } \\
\text { studied }\end{array}$ & $\begin{array}{l}\% \text { of bones with } \\
\text { ' } 0 \text { ' N.F. }\end{array}$ & $\begin{array}{l}\% \text { of bones with } \\
\text { ' } 1 \text { ' N.F. }\end{array}$ & $\begin{array}{l}\% \text { of bones with } \\
\text { ' } 2 \text { ' N.F. }\end{array}$ & $\begin{array}{l}\% \text { of bones with } \\
\text { '>3' N.F. }\end{array}$ \\
\hline Mysorekar ${ }^{11}$ & 180 & $3.3 \%$ & $45 \%$ & $50 \%$ & $1.6 \%$ \\
\hline Laing $^{12}$ & 10 & 0 & $60 \%$ & $40 \%$ & 0 \\
\hline Motabagani ${ }^{14}$ & 130 & $3.07 \%$ & $48.46 \%$ & $48.46 \%$ & 0 \\
\hline Roopam et al ${ }^{7}$ & 312 & 0 & $44.6 \%$ & $49.4 \%$ & $6.1 \%$ \\
\hline Present Study & 100 & $3 \%$ & $71 \%$ & $25 \%$ & $1 \%$ \\
\hline
\end{tabular}

\begin{tabular}{|c|c|c|c|c|c|c|c|}
\hline Author & $\begin{array}{l}\text { Total } \\
\text { bones }\end{array}$ & Total NF & LS & MS & LA & ML & LL \\
\hline Mysorekar ${ }^{11}$ & 180 & 270 & $4.8 \%$ & $14.4 \%$ & - & - & - \\
\hline Roopam et al ${ }^{7}$ & 312 & 511 & $4.7 \%$ & $16.6 \%$ & $53 \%$ & $40.9 \%$ & $12.1 \%$ \\
\hline Present Study & 100 & 124 & $58.8 \%$ & $26.6 \%$ & $00 \%$ & $1.6 \%$ & $12.9 \%$ \\
\hline
\end{tabular}

LS= Lateral Surface; MS= Medial Surface; LA= Linea Aspera; LL= Lateral Lip; ML= Medial Lip.

Table VIII: Comparison of the location of the nutrient foramina on surface of femur.

\begin{tabular}{|l|c|c|c|}
\hline Author & Total no. of NF & Dominant NF & Accessory NF \\
\hline Kizilkanat et al $^{10}$ & 124 & $80.64 \%$ & $19.35 \%$ \\
\hline Roopam et al & 511 & $77.1 \%$ & $22.9 \%$ \\
\hline Present Study & 124 & $64.5 \%$ & $35.4 \%$ \\
\hline
\end{tabular}

Table IX: Comparison of the size of the nutrient foramina in terms of dominant and accessory. 


\section{Location of nutrient foramina}

\section{On the anatomical surface of the femur}

The nutrient foramina were located on variable anatomical surfaces of the femur. This was studied and compared with the other authors in Table VIII. The most common location of nutrient foramen was on lateral surface, which defers from the previous authors. For medial surface results are almost similar to previous authors. Regarding the location of nutrient foramen on the lateral lip, the result are similar to Roopam et al. ${ }^{7}$ No nutrient foramen was found on linea aspera.

(ii) Location of nutrient foramina on the corresponding '1/3' segment from the upper end of the femur

The location of the nutrient foramina on the femur with respect to the ' $1 / 3$ ' segment of the total length of the bone from the upper end was documented in this study. Maximum number (78.2\%) of nutrient foramina were found on middle $1 / 3$ segment of the femur. Next maximum number $20.9 \%$ of nutrient foramen was found in proximal 1/3 segment of femur. The authors Mysorekar ${ }^{11}$ Kizilkanat et al $^{10}$ Longia et al ${ }^{17}$ Nagel $^{15}$ Kirschner et al $^{16}$ reported that the nutrient foramina are mostly located in the middle one-third of the diaphysis. Our results are similar to their findings.

\section{Caliber of the nutrient foramen}

The size or caliber of the nutrient foramina was determined (dominant and accessory) and the results compared with other authors. In our study the percentage of dominant foramen was less (64.5\%) and that for accessory foramen was higher (35.4\%) as compared to previous authors as shown in Table IX

\section{CONCLUSION}

The mean total length of femur obtained was $41.22 \mathrm{cms}$. Femur was found to have variable number of nutrient foramina, ranging from 1 to 3 , on a single bone. The most common location was on the lateral surface (73\%), on the linea aspera nutrient foramen was absent. According to present study the commonest location of NF was on the middle third segment of femur. The total number of NF studied was 124, dominant NF were $64.5 \%$ and accessory NF were $35.4 \%$. However the study of large sample is required to give a conclusive opinion regarding the importance of this type of study in clinical practice.

\section{REFERENCES}

1. Laroche M. Intraosseous circulation from physiology to disease. Joint Bone Spine. 2002;69:262-9.

2. Al-Motabagani, MAH. The arterial architecture of the human femoral diaphysis. J Anat Soc India. 2002;51(1):27-31.

3. Standring S, Collins P, Wigley C, editors. Gray's Anatomy. $39^{\text {th }}$ ed. London: Elsevier Churchill Livingstone; 2005 .p.93-6.

4. Craig JG, Widman D, Van HM. Longitudinal stress fracture: patterns of edema and the importance of the nutrient foramen. Skeletal Radiol. 2003;32:22-7.
5. Longia GS, Ajmani ML, Saxena SK, Thomas RJ. Study of diaphyseal nutrient foramina in human long bones. ActaAnat (Basel). 1980;107(4):399-406.

6. Williams PL, Dyson M, editors. Gray's Anatomy. $37^{\text {th }}$ ed. London: Elsevier Churchill Livingstone; 1992. p.299-300.

7. Gupta RK, Gupta AK. A study of diaphyseal nutrient foramina in human femur. Int J Res Med Sci. 2016 Mar;4(3):706-12. DOI: http://dx.doi.org/10.18203/2320-6012.ijrms20160496

8. Henry H. A Hoeber Medical Book. New York: Harper and Row; 1962. p.24, 182,408.

9. Schaeffer JP. Morris "Human Anatomy". $11^{\text {th }}$ ed. Philadelphia; Mcgraw Hill Book Company Inc.: 1953. p.91, 217, 253,255,262.

10. Kizilkanat E, Boyan N, Ozsahin ET, Soames R, Oguz O. Location, number and clinical significance of nutrient foramina in human long bones. Ann Anat. 2007;189(1):87-95.

11. Mysorekar VR. Diaphysial nutrient foramina in human long bones. J Anat. 1967;101:813-22.

12. Laing PG. The blood supply of the femoral shaft: An anatomical study. J Bone Jt Surg. 1953;35B(3):462-6.

13. Bridgeman $G$, Brookes $M$. Blood supply to the human femoral diaphysis in youth and senescence. J Anat. 1996;188:611-21.

14. Motabagani. The arterial architecture of the human femoral diaphysis. J Anat Soc India. 2002;51(1):27-31.

15. Nagel A. The clinical significance of the nutrient artery. Orthop. 1993;22:557-61.

16. Kirschner MH, Menck J, Hennerbichler A, Gaber O, Hofmann GO. Importance of arterial blood supply to the femur and tibia for transplantation of vascularized femoral diaphyses and knee joints. World J Surg. 1998;22(8):845-51.

17. Longia GS, Ajmani ML, Saxena SK, Thomas RJ. Study of diaphyseal nutrient foramina in human long bones. Acta Anat (Basel). 1980;107(4):399-406. 